\title{
PER UN PLANTEJAMENT DEMOCRATTIC DE LA LLUITA DE LES DONES *
}

\author{
Giulia Adinolfi
}

Aquest article planteja, ja des del 1967, una discussió sobre les diferents concepcions de l'opressió de la dona i d'allò que han de ser les seves formes d'organització i de lluita. L'autora assenyala tres concepcions sobre la lluita de la dona que, segons ella, són errònies. La primera considera la lluita de les dones com un moviment de solidaritat amb els seus companys. La segona, la feminista, separa la lluita de la dona de la lluita d'altres grups de la societat. Finalment, la tercera converteix la lluita de la dona en una cosa secundària respecte a la lluita contra el capitalisme.

Aquest mateix tipus de discussió sorgeix avui en els grups feministes $i$ en els grups polítics, i per això sembla interessant reproduir-lo com un treball peoner sobre el tema a Espanya.

* Reproducció de «Nous Horitzons», núm. 12, 1967. Va ésser publicat per primera vegada sota el pseudònim de Lluïsa Vives. 


\section{Nota preliminar}

Al volver a leer, al cabo de más de diez años, este texto, lo primero que llama la atención son las insuficiencias y las limitaciones de los planteamientos que entonces se hacían, el cambio profundo de las condiciones en que se pone hoy la cuestión femenina, y, por tanto, el envejecimiento de aquellas propuestas. Sin embargo, a pesar del evidente deterioro provocado por el tiempo, pienso que este texto conserva todavía un cierto valor.

En primer lugar, el valor de un documento histórico. Sobre éste vale la pena reflexionar en un momento en el cual la participación de las mujeres de este país en la lucha antifranquista se juzga a veces, por parte de militantes feministas, como un momento irrelevante $\longrightarrow$, incluso, si no negativo, desviante- en el proceso de toma de conciencia de su específica explotación. Después de la guerra y la derrota, una primera reflexión colectiva sobre la condición femenina nació en España estrechamente relacionada con la participación de las mujeres en la lucha general. El texto, en efecto, más que la expresión de un punto de vista personal, es el resultado de una experiencia de lucha concreta y de una larga discusión de un colectivo del PSUC. Así pues, cuando se afirma que la conciencia de la discriminación femenina ha sido frenada por la incapacidad del PSUC y del PCE de reconocer lo específico del movimiento de mujeres, habría que haber dicho antes que fue la lucha del PSUC y del PCE la que la resucitó, la que la hizo de nuevo posible.

Además de su valor histórico, pienso que algunas de las consideraciones que entonces hacíamos tienen todavía actualidad, porque, si es cierto que las condiciones de la lucha de las mujeres son hoy muy distintas, no lo son radicalmente. $Y$ no aludo a la insistencia con que entonces defendiamos lo específico femenino dentro de la lucha general, consideración demasiado evidente hoy como para que sea necesario seguir recordándola. Lo que no me parece todavía asumido - diría incluso que menos que entonces, no 
sólo en la práctica política, sino también en la conciencia que la inspiraes la concepción, que se formula en el texto, según la cual la política de masas no es sólo un instrumento táctico del proletariado, sino la afirmación de su carácter hegemónico. Evidentemente este problema no afecta sólo a las mujeres y a su lucha, pero es éste uno de los terrenos donde más claramente se evidencian las debilidades de un planteamiento equívoco de las alianzas del proletariado. Con otras palabras, al reafirmar la validez de aquella concepción quiero decir dos cosas: que, como entonces, no creo en la viabilidad de un verdadero proceso emancipatorio femenino al margen del proyecto revolucionario del proletariado; y que, como entonces, creo que el proletariado tiene que asumir como suyas todas las luchas contra el mal social, que su proyecto final, presente en sus luchas cotidianas, tendría que ser no sólo el de cambiar las relaciones de producción, sino, con ellas, el de cambiar la vida. 
És significatiu l'interès actual que per la «dona» -i, per tant, per les masses femenines- demostren nuclis polítics i parapolítics importants, sobretot catòlics, en revistes, publicacions, etc. Aquest interès, a més d'expressar la temptativa, per part de certs grups, de revisar actituds i sensibilitats anacròniques fins $i$ tot a Espanya enfront del problema de la dona dins la societat actual, revela al mateix temps com aquestes forces consideren importants i disponibles les masses femenines.

De tota manera, per afirmar que la «disponibilitat» de les dones avui ha canviat, no cal recórrer a aquesta prova indirecta. Hi ha senyals evidents d'una naixent inquietud política entre les dones. És a dir, existeix una difusa - bé que sovint encara genèrica - voluntat de participació activa, de compromís responsable, d'iniciativa política. La importància -i la garantia- d'aquests primers senyals d'una revifalla política de les dones està, sobretot, en la coincidència d'aquest fenomen amb el moviment general de renovació que anima la classe obreta i altres sectors del país, en un moment en què la classe dirigent, per les característiques de la fase de desenvolupament que travessa avui la societat espanyola, es revela incapaç de contenir dins les velles fórmules de pressió les contradiccions que l'esquincen.

Tanmateix, això no ha de fer subvalorar — sinó, al contrari, desemmascarar $i$ combatre- les temptatives que grups de la classe dirigent estan portant a terme per a superar - ni que sigui a nivell de pures afirmacions i amb contradiccions evidents- alguns aspectes d'aquesta crisi. A més, en el cas de les dones el pes d'una campanya de pressió ideològica, bé que sigui només demagògica, és força inquietant, perquè aquesta pressió constitueix des de sempre en les societats burgeses una forma important de contenció de les masses femenines. Enfront del desgast evident que ha sofert en la consciència collectiva la vella concepció de la dona, definida únicament com a esposa $i$ mare, es perfila així l'intent d'aplegar les energies de les dones cap a una afirmació de la pròpia personalitat subtilment i profundament equívoca - $\mathrm{i}$ per això mateix força perillosa- a través 
d'una nova concepció de la dona que posa al dia els vells esquemes de la feminitat acoblant-los $i$ adaptant-los al nou paper de «consumidora», que els interessos constituiits li atribueixen.

L'èxit, o no, d'aquesta operació dependrà indubtablement de molts factors, però segurament en gran mesura de la capacitat de replicar-la i combatre-la. D'aquí, doncs, la necessitat i la urgència de reconsiderar, en el seu complex, quina ha d'ésser l'autèntica política democràtica de les dones. Les forces que volen un profund renovament del país tenen, efectivament, consciència d'aquesta exigència. Però — repetim-ho- no es tracta tan sols de prestar atenció als problemes de la societat catalana i espanyola en conjunt: es tracta d'elaborar una plataforma política general, clara i coherent, per a la solució d'aquests problemes. Direm més encara: que aquesta formulació política general visqui dins la consciència concreta de les forces democràtiques, que actuï coherentment en les seves tries i en les seves decisions polítiques a tots els nivells.

Ara bé: és justament aquesta clara consciència collectiva el que manca. En el camp mateix de les forces més tenaçment o conscienciosament compromeses a realitzar una profunda transformació de la societat coexisteixen encara plantejaments polítics diversos, equívocs $i$ contradictoris $i$ tot sobte la lluita de les dones. Potser serà útil, doncs, de començar precisament amb l'anàlisi d'aquestes concepcions encara persistents i operants, en l'intent de definir i aclarir a través d'aquesta confrontació crítica una concepció autènticament democràtica de la lluita de les dones.

La concepció que més tenaçment persisteix entre les forces socialistes és bastant difícil de definir perquè, més que en fórmules generals i explícites, es manifesta en la praxis política. Aquesta concepció, tanmateix, consisteix a considerar la lluita de les dones com inspirada fonamentalment per una intuitiva i emotiva solidaritat amb la de llurs marits i llurs fills: així, a la inversa, aquests defensen per motius anàlegs les reivindicacions i la lluita de les dones. En definitiva, la lluita subalterna, que no es proposa objectius específics parcials, sovint contingents, més sovint encara nascuts d'iniciatives i de la lluita en altres terrenys.

Que quedi ben clar que allò que ara està en discussió és la manera de concebre la lluita. La constatació que avui, en les condicions actuals, la lluita de les dones sigui encara necessàriament dispersa, que es proposi encara objectius parcials, pertany a un ordre de consideracions diferent: demostraria, en tot cas, que un moviment polític no pot realitzar plenament els seus objectius des dels seus inicis, no pas que els hagi d'ignorar. I, d'això, precisament, es tracta: ‘és just, en aquest moment i al nostre país, concebre - i per tant dirigir i organitzar- la lluita de les dones 
únicament com una lluita subalterna, com una forma de suport $i$ solidaritat amb la d'altres sectors, sense esforçar-nos a trobar-li una perspectiva pròpia i específica?

La concepció que critiquem conté la renúncia implícita a l'elaboració d'aquesta perspectiva més àmplia. Aquesta renúncia no neix sols de les limitacions externes, de les dificultats materials indubtablement existents per a desenvolupar la lluita de les dones: neix també d'unes implícites limitacions de fons, d'uns errors teòrics en jutjar la naturalesa i l'origen dels problemes femenins.

Primer de tot, ni que sigui inspirada per les millors intencions, aquesta concepció enclou de fet una consideració de la dona com a ésser especialment necessitat de protecció, com a eterna menor d'edat, com a inferior. Implícitament s'accepta i es confirma així la discriminació de què la dona és víctima dins la societat capitalista $i$, per tant, no es facilita - tot al contrari- la presa de consciència collectiva de la injustícia d'aquesta discriminacio.

Però sobretot - $\mathrm{i}$ això és bastant més greu- sembla que se n'ignorin les causes estructurals, és a dir, l'estret lligam que existeix entre explotació del treball en general i condició d'inferioritat en què és mantinguda la dona. Ara bé, quan es desconeix o se subvalora la funció que té dins el mercat del treball la mà d'obra femenina -és a dir, el fet que l'explotació de tota la mà d'obra s'obté mantenint intencionalment la dona en condicions d'inferioritat per exercir una pressió sobre el mercat del treball en conjunt-, no solament es perjudica la causa de les dones, sinó la lluita general del proletariat.

Les conseqüències d'aquesta concepció insuficient de la lluita de les dones en la praxis política són -i s'hi fan cada dia més- igualment greus. Aquestes poden, força esquemàticament, resumir-se així:

1. Una instrumentalització inconscient de les masses femenines, en la incapacitat de copsar les possibilitats objectives d'una autèntica política de masses. Això és sobretot greu pel fet que aquestes masses estan en gran majoria directament (si bé no conscientment) interessades en la lluita del proletariat: és a dir, hi estan interessades no solament les dones proletàries, sinó, potencialment, les camperoles, les empleades, les intellectuals, les estudiantes, les dones mateixes de la petita burgesia. La persistència, de fet, de la condició d'inferioritat avui és deguda fonamentalment a l'interès del capitalisme a mantenir determinades condicions d'explotació de les forces del treball. Víctimes, directes o indirectes, d'aquesta explotació són, doncs, la gran majoria de les dones. La qual cosa no significa, naturalment, que les dones se sostreguin a l'actual divisió en classes de la 
societat, sinó que la classe burgesa no sols no representa els interessos de la majoria de les dones, ans tampoc no defensa els interessos de les dones burgeses en tant que són dones, i sí, en canvi, en tant que pertanyen a la classe social.

Per a promoure, doncs, un moviment femení, cal no solament inspirar-se en un genèric sentiment de solidaritat, sinó aclarir que les raons d'aquesta solidaritat neixen objectivament de la identitat d'objectius i problemes entre la majoria de les dones, d'una banda, i la classe obrera, de l'altra, en primer lloc, $i$ tots els grups socials interessats en la transformació de la societat.

2. S'empobreix la lluita política del proletariat en sostreure'n un tema - l'alliberació de la dona- que li és naturalment i tradicionalment propi. En efecte, el proletariat és l'única classe capaç de resoldre el problema de la dona, l'única classe que en combatre contra l'explotació del treball combat alhora per eliminar la causa social més profunda de la discriminació de la dona.

3. Es fragmenta la lluita, se l'esgota en objectius parcials, en arrencar-la de la perspectiva general i final. En canvi, la presència en la perspectiva de la lluita democràtica d'objectius com l'alliberació real de la dona és, d'una banda, un estímul fecund i idealment eficaç per accelerar el procés en totes les seves etapes, i, de l'altra, assegurar als objectius parcials una significació no contingent, inserint-los en un procés continu $i$ ascendent.

Una altra, i gairebé diametralment oposada, concepció de la lluita de la dona és la que per comoditat de referència i per analogia anomenarem «concepció feminista». També en aquest cas, més que davant unes formulacions explícites $i$ orgàniques, ens trobem - $i$ molt sovint - enfront d'uns residus, a vegades incoherents, d'una concepció «feminista». D'aquí, doncs, la utilitat d'una discussió d'aquesta concepció en el seu complex, per tal de superar a l'origen les disparitats de criteri sobre casos particulars, que d'aquella concepció deriven.

La concepció feminista de la lluita de les dones parteix de l'afirmació que el problema central de la dona és el de la seva discriminació al si de la societat $i$, per tant, que l'objectiu central de la seva lluita ha d'ésser el de la seva emancipació. Cal estar perfectament d'acord en aquesta afirmació: la disparitat comença quan s'analitza quina és concretament dins la nostra societat la causa d'aquesta discriminació. La posició feminista consisteix a subvalorar la causa estructural d'aquesta discriminació i a concebre l'emancipació de la dona com a possible dins el marc de la mateixa societat que modernament la manté. Concretament, la discriminació de la dona fóra 
una incongruència, una cosa sense sentit, un residu anacrònic, que ja no es justifica des del moment en què la dona ha entrat en la producció industrial. Al contrari, és evident que la discriminació de la dona és coherent amb la llei de màxim benefici que regula la societat si no canvia aquesta a través d'una lluita per profunds canvis d'estructura.

Un exemple típic de la concepció «feminista» és la sobrevaloració de la funció alliberadora del treball social per a la dona: entrar en la producció social és la panacea de tots els mals que la dona sofreix actualment. Al contrari, l'ingrés de la dona en la producció industrial és precisament la causa moderna de la seva explotació $i$, en conseqüència, de la condició d'inferioritat en què actualment es troba. L'ingrés de la dona en la producció social és alliberador només en tant que li ofereix la consciència dels seus drets, la possibilitat de formes organitzades de lluita $i$, sobretot, l'íntima solidaritat de tot el món del treball igualment interessat a combatre l'explotació capitalista.

Finalment, una concepció «feminista» dels problemes de la dona és ingènuament optimista en les confrontacions del paper de l'educació en el procés d'alliberament de la dona, gairebé com si la causa de la discriminació consistís en l'escassa consciència que les dones tenen de llurs drets. Es desconeix, en canvi, que, donades les especials característiques de l'explotació de les dones - és a dir, donada la importància del moment «ideologic» com a instrument d'aquesta explotació-, la consciència de les dones només pot néixer de la lluita i no en pot ésser pas la premissa.

Tanmateix, el que més preocupa i empeny a una clarificació definitiva són les conseqüències polítiques d'una tal concepció. Quines són aquestes conseqüències?

1. En subvalorar les causes socials de la discriminació de les dones, no es reconeixen les relacions que hi ha entre lluita femenina i lluita general per la renovació del país. Aquest és un punt sobre el qual cal insistir: la lluita general i la lluita específica de les dones coincideixen, són moments inescindibles d'una única lluita. L'alliberació de la dona serà el resultat de la lluita general, a la qual hauran contribuït homes i dones: la contribució de les dones pot i deu ésser específica, però serà important en la mesura que coincidirà amb la lluita pel renovament de la societat.

2. Se subvaloren, doncs, el pes, la importància que tenen en la lluita de les dones els problemes generals de la societat, que en aquest moment interessen $i$ afecten profundament les masses femenines, com ara els problemes de la casa, de la carestia de la vida, de l'educació dels fills. De fet, existeixen, actualment, dues categories de problemes que interessen les masses femenines: els que neixen de la discriminació de la dona dins la 
societat; i d'altres problemes, com els que he assenyalat, els quals, malgrat ésser comuns a homes $\mathrm{i}$ dones, condicionen avui de manera decisiva la vida, les possibilitats, les aspiracions mateixes de grans masses de dones. La concepció «feminista» de la lluita de les dones tendeix a subvalorar aquest segon nucli de problemes, a considerar-lo, en el millor dels casos, instrumentalment, $o$, fins $i$ tot, a jutjar-lo perillós com a terreny de lluita, pel fet que bloquejaria les dones al voltant d'uns temes i d'uns problemes, dels quals, en canvi, sobretot i abans que res, haurien d'alliberar-se. Aquests problemes, al capdavall, no serien els veritables, els autèntics problemes de la dona.

Ara bé, no solament aquests problemes són avui els principals entrebancs que les dones troben en el camí de llur emancipació, sinó que la sensibilitat de les masses femenines per aquests problemes revela que aquestes masses són ja intuïtivament capaces de reconèixer en les estructures de la societat actual - d'on sorgeixen directament i immediatament aquells problemes - les causes de la injustícia que elles pateixen. Ignorar o menysprear, per tant, aquests problemes en el moment de concebre i organitzar un moviment femení significa abocar de nou les dones cap al cul-de-sac d'un feminisme reformista petitburgès.

Una tercera concepció de la lluita de les dones mereix igualment atenció crítica. També aquí, per a facilitar-ne les referències, li donarem un nom: l'anomenarem concepció «extremista», bé que, com veurem pel context, sigui ben poc revolucionària. És una tesi bastant difosa $i$ no solament a casa nostra: la sostenen a Itàlia nuclis importants de comunistes i fou defensada en un congrés no gaire llunyà de les dones per la delegació xinesa. A Espanya se sol trobar sobretot en ambients intellectuals.

Els problemes de la dona - diuen- neixen del contrast antagònic entre capital i treball. Els problemes de la dona, doncs, no poden ésser resolts si no és amb la inversió total de les estructures actuals de la societat, és a dir, dins el marc d'una societat socialista. El primer, i únic, problema d'un revolucionari és el canvi d'estructures, que són la base d'allò que ell combat: el problema de la dona, com molts altres problemes de la societat, és un problema secundari, que depèn del primer.

Per tant, la lluita de les dones coincideix i ha d'inserir-se completament dins la lluita de classe: la creació de moviments de massa femenins no sols és inútil - pel fet que la solució dels problemes de la dona vindrà només del canvi d'estructures, resultat mecànic d'aquest-, sinó també perillosa, ja que si la dona dins la societat actual és discriminada, no és permissible, al seu torn, de discriminar per a combatre la discriminació. 
Aquesta concepció és un exemple típic de com unes afirmacions generals justes, però incompletes, poden portar a conseqüències errades per manca de sentit polític. En efecte, és veritat que els problemes de les dones neixen del contrast entre capital i treball, però reflecteixen al mateix temps una contradicció «interna» de la societat capitalista entre tendències objectives d'aquesta societat (concretament: nova divisió del treball, introducció de la dona en la producció industrial, socialització de funcions - com educació dels fills o atenció sanitària - abans confiades a elles, etc.), i altres trets de fet de la mateixa societat (com l'interès a mantenir, a través de les institucions, de la pressió ideològica, etc., una determinada situació anacrònica de la dona). Això significa que l'alliberació de la dona no interessa exclusivament la classe obrera, sinó també capes diverses i força extenses de la població.

Una altra consideració de fons és que, darrera les afirmacions «extremistes» que hem esmentat, s'amaga una concepció màgica i escatològica de la revolució. La conquesta del poder i la construcció d'una societat socialista són, tanmateix, uns processos complexos en què el canvi d'estructures representa certament el nus central però que no poden ésser concebuts aillant-los de llur projecció temporal, del present que els prepara i del futur que els realitza a tots els nivells.

$\mathrm{Al}$ costat d'aquestes consideracions generals és important d'observar com una concepció que confii la solució dels problemes de les dones només i únicament al canvi d'estructures porta com a conseqüència a greus errors polítics. Aquests errors, breument, són:

1. Negació implícita i subvaloració pràctica de la política de masses. Ara bé, aquesta política no sols és un instrument tàctic del proletariat, sinó l'afirmació, ja avui, del caràcter hegemònic del proletariat, de la seva - capacitat i possibilitat de resoldre els problemes de la societat en el seu conjunt. Desconèixer això significa fer retrocedir el proletariat cap a una forma ja superada de consciència de classe, estretament lligada a interessos particulars, corporatius.

2. Empobriment de la lluita del proletariat, en rebutjar les formes concretes $\mathrm{i}$ històricament determinades que d'aquesta lluita se li ofereixen, per jutjar-les indignes dels seus objectius revolucionaris. Per contra, aquests objectius poden concretament realitzar-se només al llarg d'un procés d'etapes successives i necessàries.

Aquests són - bastant breument i esquemàticament- els principals temes en discusió entre aquells que es proposen de trobar el veritable, l'autèntic terreny per a la lluita democràtica de les masses femenines. És evident que la decisiva clarificació de tots aquests problemes naixerà en defi- 
nitiva de l'experiència concreta de la lluita de les dones, així com és cert que la manca d'aquesta experiència és causa decisiva de la confusió i la desorientació encara existents. Però també és certa l'afirmació inversa: és a dir, que l'escassa o insuficient visió política dels problemes de les dones ha impedit, en part, o ha entrebancat, durant aquests anys, l'esbargiment de les dificultats externes resistents a l'esforç combatiu de nuclis de dones d'avantguarda; i que —-preocupació aquesta bastant més greu- la persistència d'aquesta insuficiència pot perjudicar l'eficàcia i la importància de la lluita, que ja comença d'estendre's a masses més àmplies, decidides a assumir un paper propi en la lluita general per la renovació del país. 